\title{
CONTRIBUIÇÕES DA TEORIA LABANIANA PARA O DESENVOLVIMENTO DO TRABALHO COM PRÁTICAS CORPORAIS NO SISTEMA ÚNICO DE SAÚDE
}

\author{
CONTRIBUTIONS OF LABANIAN THEORY TO DEVELOPING WORK WITH \\ BODILY PRACTICES IN BRAZIL'S UNIFIED HEALTH SYSTEM
}

APORTACIONES DE LA TEORÍA DE RUDOLF LABAN AL DESARROLLO DEL TRABAJO CON PRÁCTICAS CORPORALES EN EL SISTEMA ÚNICO DE SALUD

\section{Andrezza Campos Moretti*, Yara Maria de Carvalho**}

\section{Palavras chave:}

Sistema Único de

Saúde. exercício e de movimento.

Educação

continuada.
Técnicas de

\begin{abstract}
Resumo: Apresentamos os resultados de uma pesquisa composta por dois campos de experimentação, entrevistas e observações sistemáticas que objetivou compreender como a teoria labaniana pode contribuir com o trabalho dos profissionais de saúde que atuam com práticas corporais no Sistema Único de Saúde. Ela contou com a participação de dez profissionais e foi implementada em dois equipamentos de saúde de São Paulo/SP/ Brasil, possibilitando discussões sobre três modos de se conduzir as práticas corporais. São eles: a observação e/ou imitação de sequências de movimento; a qualidade das interações verbais; a diversificação de estratégias didáticas. Verificou-se que a teoria labaniana atuou, nesses casos, na constituição e no aprimoramento do trabalho com as práticas corporais e concluiu-se que ela é um importante referencial para a formação de profissionais que atuam com tais ações, o que aponta para a necessidade de se investir na difusão desse referencial nos serviços públicos de saúde.
\end{abstract}

Keywords: Unified Health

System.

Exercise Movement

Techniques.

Continuing

Education.

Palabras clave: Sistema Único de Salud.

Técnicas de Ejercicio y de Movimiento. Educación Continuada.

\begin{abstract}
We present the results of a research including two fields of experimentation, interviews and systematic observations aimed at understanding how Labanian theory may contribute to the work of health professionals with bodily practices in Brazil's Unified Health System. Participants were ten professionals and it was implemented in two health facilities in São Paulo, SP, Brazil, enabling discussions about three ways of conducting bodily practices: observation and/or imitation of movement sequences; quality of verbal interactions; diversifying teaching strategies. It found that Labanian theory worked, in these cases, in the constitution and improvement of the work with the bodily practices and it is an important reference for training professionals who do such work, pointing to the need to invest in the dissemination of this framework in public health services.
\end{abstract}

Resumen: Presentamos los resultados de una investigación compuesta por dos campos de experimentación, entrevistas y observaciones sistemáticas, cuyo objetivo era comprender cómo la teoría de Laban puede contribuir al trabajo de los profesionales de salud que actúan con prácticas corporales en el Sistema Único de Salud. Se contó con la participación de diez profesionales y se implementó em dos centros sanitarios en São Paulo/SP/Brasil, permitiendo discusiones sobre tres modos de conducir las prácticas corporales. Son ellos: la observación y/o imitación de secuencias de movimiento; la calidad de las interacciones verbales; la diversificación de estrategias didácticas. Se constató que la teoría de Laban actuó, en estos casos, en la constitución y mejora del trabajo con las prácticas corporales y se concluyó que es una referencia importante para la formación de profesionales que trabajan con estas acciones, lo que indica la necesidad de invertir en la difusión de esta referencia en los servicios públicos de salud.
*Instituto Federal de Educação, Ciência e Tecnologia de São Paulo. Sorocaba, SP, Brasil.

E-mail: azmoretti @ifsp.edu.br

**Universidade de São Paulo. São Paulo, SP, Brasil.

E-mail: yaramc@usp.br

Recebido em: 15-04-2019 Aprovado em: 23-11-2019 Publicado em: 19-12-2019

DOI: https://doi.org/10.22456/1982-8918.91900

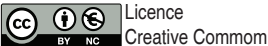




\section{INTRODUÇÃOO}

As práticas corporais são consideradas tecnologias capazes de atender às necessidades de saúde da população. São encontradas nos serviços públicos de saúde por possibilitarem a ampliação da autonomia e da corresponsabilidade dos usuários no cuidado com a saúde, por auxiliarem no cumprimento de direitos assegurados pela Constituição Federal e por estarem elencadas em algumas políticas públicas, como a Política Nacional de Promoção da Saúde e a Política Nacional de Práticas Integrativas e Complementares.

Isso ocorre porque o Ministério da Saúde destina recursos financeiros para a capacitação dos profissionais de saúde que desejam atuar ou já atuam com tais práticas no Sistema Único de Saúde. Contudo, os documentos oficiais que regulamentam tal ação não apresentam informações precisas sobre por que, qual o sentido, quais conteúdos e estratégias didático-pedagógicas devem ser apreendidos. Indicam, apenas, que as capacitações sejam executadas na lógica da educação permanente e recomendam que os profissionais sejam capazes de: implantar modalidades de práticas corporais; realizar ações de aconselhamento visando estimular comportamentos ativos e saudáveis; mobilizar parcerias para a disseminação das atividades implementadas; avaliar e monitorar os programas vigentes; produzir evidências que comprovem a efetividade das práticas corporais na prevenção das doenças crônicas e agravos não transmissíveis (BRASIL, 2006a; 2006b).

Consequentemente, é frequente encontrar profissionais que incentivam os usuários a andar, correr e se exercitar de uma forma mecânica, repetitiva, desconectada das necessidades e dos seus próprios interesses e desconsideram que:

Movimentar-se [...] pressupõe conhecer limites e possibilidades na dimensão física, biológica, fisiológica, mas também intelectual, emocional e afetiva que determina, por sua vez, a subjetividade da pessoa. Enquanto nos movimentamos pensamos, sentimos, inventamos e recriamos a vida (CARVALHO, 2007, p.65).

Para que as práticas corporais possam ser consideradas recursos direcionados à promoção e à produção de saúde, elas precisam instigar o protagonismo das pessoas. Para tanto, o profissional que conduz os encontros precisa saber mobilizar, discutir, produzir e partilhar conhecimentos sobre o corpo em movimento que possam ser usados no cotidiano, que realcem a amizade, a solidariedade, auxiliem na construção de vínculos e no reconhecimento do que sentem ao agir intencionalmente. Sem isso, as práticas corporais acabam limitadas às orientações da mídia e à melhora das condições físicas e biológicas da saúde e não propiciam um olhar diferenciado para as potencialidades corporais, para os relacionamentos, para a saúde e para a vida.

A teoria labaniana pode contribuir com esse propósito e auxiliar no entendimento de qual o rigor e o núcleo de saberes envolvidos nesse trabalho, pois através da apresentação e mobilização de princípios ligados a quatro fatores (Espaço, Peso, Tempo e Fluência) permite a compreensão da mecânica, da qualidade, do desejo e do processo decisório que precedem e acompanham os movimentos corporais humanos (LABAN, 1978, 1990). Ao invés de propor passos e sequências de movimento predefinidas, ela expõe e discute processos pedagógicos que podem auxiliar o professor a planejar e desenvolver atividades criativas direcionadas ao reconhecimento das limitações e aprimoramento das potencialidades do sujeito. Desse modo, neste artigo, estão os resultados de uma pesquisa que objetivou compreender como ela pode 
contribuir com o trabalho dos profissionais de saúde que atuam com práticas corporais no Sistema Único de Saúde.

\section{METODOLOGIA}

Para selecionar o território em que esta investigação seria executada, primeiramente, foram consideradas a acessibilidade da local, a existência de um programa ${ }^{1}$ que regulamentasse a operacionalização das práticas corporais, a existência de publicações científicas relativas às ações com as práticas na jurisdição e a preexistência de vínculos ${ }^{2}$ com profissionais da região.

Consecutivamente, a proposição foi apresentada a vários profissionais da Secretaria Municipal de Saúde local, responsáveis por autorizar a execução do trabalho. Com retornos positivos a pesquisa foi encaminhada e aprovada pelo Núcleo de Educação Permanente ${ }^{3}$ (NEP), pelo Comitê de Ética em Pesquisa da Secretaria Municipal de Saúde de São Paulo (Processo n-0008.0.162.342.10) e foi implementada no segundo semestre de 2013.

Neste período, foram realizados dois campos de experimentação, registrados através de observações participantes e entrevistas semiestruturadas. Os campos de experimentação ocorreram no Centro de Cooperação e Convívio "Eduardo Leite Bacuri" (CECCO) e na Unidade de Medicinas Tradicionais (UMT), que presta serviços de cunho ambulatorial e policlínico, localizados na área de abrangência da Coordenadoria Regional de Saúde Centro-Oeste, em São Paulo/SP/Brasil. Esses locais foram escolhidos porque, além de atenderem aos requisitos preliminares, tinham finalidades assistenciais distintas, dispunham de espaços para que encontros ocorressem e reuniam vários sujeitos que atuavam com práticas corporais. Após a apresentação da proposta para essas equipes de saúde e convite aos profissionais que ministravam práticas corporais há mais de dois anos, quatro dos que trabalhavam no CECCO e seis dos que atuavam na UMT aceitaram contribuir.

Desses dez sujeitos, nove eram do sexo feminino e um do masculino, quatro eram graduados em Psicologia, dois em Terapia Ocupacional, dois em Serviço Social, um em Nutrição e um era técnico em administração. Sete ensinavam Tai Chi Pai Lin, três Lian Gong em 18 terapias, dois ministravam aulas de ioga, dois de Meditação, dois de Xian Gong, dois de Reflexologia Podal e cinco respondiam por outras práticas, como caminhada, percepção corporal e culinária. Para preservar o anonimato, foram atribuídos nomes femininos fictícios a todos os participantes. Amanda, Bruna, Mariana e Thainá atuavam no CECCO e Aline, Lia, Mary, Mônica, Priscila e Rosa atuavam na UMT.

Em cada local foram realizados dez encontros de quatro horas. Nestes, foram abordados os dezesseis temas de movimento propostos por Laban (1990) no livro "Dança Educativa Moderna" e orientações relacionadas ao uso de tais conteúdos, pois os temas devem ser usados como apoio para o trabalho do professor e não como regra ou padrão rigoroso a ser seguido.

\footnotetext{
1 O programa "Qualidade de Vida com Medicinas Tradicionais", regulamentado pela lei nº. 14.682 de 30 de janeiro de 2008 e pelo decreto nํ. 49.596 de 11 de junho de 2008 subsidia as ações dos profissionais de saúde que atuam com práticas corporais na cidade de São Paulo.

2 As duas autoras têm outras pesquisas e publicações realizadas neste território. Consequentemente, já conheciam os trâmites necessários para ir "a campo". Contudo, é importante salientar que nenhuma tinha vínculo com as participantes deste estudo.

3 O NEP é composto por profissionais de várias áreas e é responsável por promover a integração entre equipamentos de rede básica, hospitalares e de urgência, instituições de ensino, instituições parceiras e conselhos gestores, incentivando a discussão dos projetos educativos.
} 
Nos dois primeiros encontros priorizaram-se os temas 1, 6 e 13 concernentes ao "Corpo", os quais favoreceram, por exemplo, o reconhecimento das partes do corpo e 0 entendimento do esforço necessário para saltar. No terceiro e no quarto foram trabalhados os temas 2, 7 e 10, relacionados ao "Esforço", propiciando, mas não só, o entendimento das conexões existentes entre os fatores peso e tempo. No quinto e no sexto encontros foram trabalhados os temas 3, 9 e 11, relacionados à exploração do "Espaço". No sétimo e no oitavo foram apresentados os temas 5, 14 e 15, vinculados aos "Relacionamentos Sociais", os quais visam à adaptação de cada sujeito ao grupo, seja pela reprodução dos movimentos percebidos, pela interação com um companheiro e/ou liderando o grupo. E no nono e décimo, os temas 4 , 8, 12 e 16, que integram os conhecimentos anteriormente apresentados e atuam, por exemplo, no reconhecimento da fluência e dos ritmos ocupacionais.

Para facilitar a identificação das estratégias didáticas usadas, os encontros foram segmentados em quatro momentos distintos. Na "sensibilização" foram propostas vivências direcionadas à integração entre as participantes e à compreensão do que seria trabalhado. $\mathrm{Na}$ "prática", foram exploradas dinâmicas (jogos teatrais, jogos de imitação, improvisações, procedimentos de composição coreográfica) que possibilitassem a experimentação das potencialidades corporais e motoras e dos temas de movimento. Foram combinadas propostas executadas em silêncio, com acompanhamento rítmico ou com músicas selecionadas e conjugadas atividades em que as participantes eram convidadas a se mover sozinhas, a se deslocar em grupos ou a se posicionar na sala livremente. No "refinamento", os repertórios de movimentos de diferentes modalidades de práticas corporais foram correlacionados e discutidos com base nas experiências vividas e conhecimentos identificados. Neste ínterim, foram averiguados aspectos mensuráveis (como a duração do movimento), itens relacionados à sensação e à participação interna (como intenção, decisão e assertividade), à qualidade do movimento e à incidência de contextos que pudessem interferir na compreensão de diferentes maneiras de ensinar e de executar as atividades. Na "finalização" era revisto o percurso trilhado, partilhados os motivos que inspiraram os procedimentos propostos, conversado sobre o que foi interessante e o que poderia ter sido diferente.

As entrevistas ${ }^{4}$ executadas antes do início, durante e após o campo de experimentação, foram gravadas e transcritas. As iniciais e as finais foram individuais.

As primeiras visaram e permitiram a compreensão de aspectos relacionados à vida e ao trabalho das participantes. Permitiram, por exemplo, identificar alguns motivos pelos quais elas atuam com as práticas corporais:

Acho que não foi uma coisa muito pensada [...]. Eu sempre tive uma coisa com o corpo, de praticar esporte. Quando menina eu jogava vôlei, jogava handebol na escola e sempre gostei muito de dança. Vivi em uma família que gosta muito de dançar. Então, eu sempre tive esse envolvimento com essa questão corporal. Acho que um pouco dessa história e um pouco do acaso que me levou para esse lado. Foi uma coisa que me deu prazer [...]. (Mariana - CECCO - E).

Compreender o processo de fundação e desenvolvimento dos equipamentos de saúde escolhidos. No caso da UMT:

[...] a ideia da criação dessa unidade era justamente pra trabalhar com o ensino e manter, dar treinamento, dar continuidade com supervisão, acompanhar os grupos formados [...] Foi difícil desde o começo porque na verdade nunca teve vontade

4 Para facilitar a identificação do local de captação das falas, após as citações diretas, será encontrado um nome feminino fictício, seguido pela localidade de atuação e por uma das siglas: $E G$ = Entrevista em Grupo, E= Entrevista inicial. 
política, o desejo era das pessoas que estavam envolvidas, das pessoas que tinham isso como meta de vida, como ideologia. [...] Quando nós viemos pra cá [...] a gente só tinha licença de funcionar se fosse atendimento à população, se fosse assistência. Ninguém queria saber de ensino. [...] nós começamos a atender e mostrar que a gente tem produtividade com práticas corporais [...] pra daí [...] poder junto com isso paralelamente continuar o ensino. (Mônica - UMT - E).

E constatar como o público-alvo compreendia o movimento, pois todo o trabalho que seria desenvolvido partiria da intersecção entre a visão delas e um ponto de vista específico: o de Laban.

As finais nos auxiliaram a entender o que cada um aprendeu nos encontros e a ratificar as informações coletadas em outros momentos da pesquisa.

As entrevistas que ocorreram ao término de cada intervenção foram grupais. Elas objetivaram o reconhecimento de semelhanças e diferenças entre as opiniões e as experiências vivenciadas, estimularam a existência de conversas sobre a teoria labaniana e discussões sobre a forma de condução da pesquisa, os conteúdos e os processos de ensino-aprendizagem estabelecidos.

Observações participantes também foram realizadas no decorrer do campo de experimentação. Embora não sejam citadas neste artigo contribuíram com a organização, com a avaliação contínua e somativa do trabalho e com a sistematização do conhecimento apreendido. Foram registradas em um diário no qual estão trilhas percorridas para a entrada em campo; informações sobre os procedimentos didáticos realizados; declarações das participantes; registros das expressões corporais observadas; comentários sobre a evolução do trabalho; correlações entre os acontecimentos e o marco teórico.

Para identificar os resultados, foi verificada a alusão direta ou indireta ao termo "Laban" nos depoimentos obtidos em todas as entrevistas e extraídos os trechos que se referiam a Laban e a sua teoria. Consecutivamente, foram selecionados aqueles que poderiam auxiliar na compreensão do que esta investigação pode ensinar sobre a formação dos profissionais de saúde que atuam com as práticas corporais no SUS, os que discriminavam as potencialidades e os déficits relativos ao uso que foi feito da teoria labaniana e os que apontavam perspectivas e possíveis desdobramentos desse trabalho. Por fim, foi estabelecido um diálogo entre 0 processo vivenciado, tais relatos e a literatura, compondo explicações para os acontecimentos.

\section{RESULTADOS E DISCUSSÃO}

Os resultados foram agrupados em quatro tópicos. Os três primeiros estão interligados, abordam e discutem modos de se conduzir as práticas corporais. O quarto revela aspectos vinculados à convivência, críticas e elogios.

\subsection{A OBSERVAÇÃO E/OU IMITAÇÃO DE SEQUÊNCIAS ESPECÍFICAS DE MOVIMENTO}

Sabe-se que grande parte do aprendizado humano e de outras espécies animais se dá por mecanismos de observação e cópia. Resumidamente, pode-se dizer que quando um sujeito observa e copia um movimento, ele se torna capaz de reconhecer a sua gestualidade e a alheia e vai, paulatinamente, ampliando o seu repertório motor (GALLAHUE; OZMUN; GOODWAY, 2013). Entretanto, observar e copiar o movimento não são processos simples. 
Os estudos desenvolvidos por Laban $(1978 ; 1990)$ mostram que os seres humanos são capazes, em graus diferentes de precisão, de denominar, descrever e reproduzir ações, chegando a perceber os estados de espírito por elas expressas. Porém, para que um sujeito possa reproduzir exatamente o que está sendo visto ele precisa ser capaz de observar sistematicamente a conduta das pessoas. Para Laban (1978), o desenvolvimento dessa habilidade exige treinamento. Ocorre quando o professor esclarece 0 que deve ser observado, refinado e vivenciado em determinada prática corporal, quando o educando tem a oportunidade de contemplar um movimento executado por outro membro do grupo, a liberdade para avaliá-lo e compará-lo com o seu (ZAGATTI, 2011). Como resultado, há a aquisição de certo vocabulário, repleto de nuances e coloridos. Trata-se de um processo lento, com muitos estágios de maturação que integram "ação, pensamento e sentimento" (LABAN, 1978, p.118).

As discussões sobre o refinamento da observação e da imitação de sequências de movimentos auxiliaram as participantes a reconhecer a mecânica das ações corporais, a compreender a importância do aprimoramento da consciência corporal, a respeitar a individualidade de cada um e a tecer discussões sobre o papel, a postura e a responsabilidade dos profissionais que atuam com as práticas corporais.

As participantes do CECCO destacaram que a teoria labaniana esclareceu como se dá o movimento e que as estratégias didáticas vivenciadas as auxiliaram a olhar e intervir com mais efetividade sobre a qualidade do movimento executada pelo usuário. Para exemplificar, há o relato de Thainá, registrado na entrevista final, no qual afirma que os encontros a tornaram mais cuidadosa, atenta e conhecedora, pois conseguiu identificar "um pouco mais a dificuldade do usuário" e "as suas", no que se refere ao modo como o corpo pode ser usado.

Depoimentos como esse mostraram que 0 trabalho com a teoria labaniana e a observação das ações corporais podem culminar no estabelecimento de relações humanizadas, no entendimento que somos diferentes e imperfeitos, no respeito e no compromisso com o outro, na percepção de que o errar não significa executar inadequadamente o movimento, mas não conseguir refletir sobre o que pode ser melhorado em termos de expressividade.

Sobre o erro, Laban (1948 apud HODGSON, 2001, p.22) escreveu: "Permita-me 0 privilégio de experimentar e ser errado, porque os testes e os erros são o fundamento de qualquer desenvolvimento saudável". Zagatti (2011) afirma que, para este autor, toda resposta considerada "errada" traz um acerto, carrega experiências e compreensões subjetivas que merecem ser compartilhadas, que transportam para o plano físico os impulsos internos do sujeito. Enfim, ao atribuir um papel importante ao erro, Laban revela uma chave educativa que proporciona aos educadores a possibilidade de atuar sobre a dimensão relacional e não a antropocêntrica.

Quanto à responsabilidade do profissional que atua com práticas corporais, os depoimentos mostraram que, para as participantes, ela vai além do ato de propor a observação ou a imitação de sequências de movimento, que ela se concretiza no rompimento de hierarquias, na possibilidade de aprender junto com o usuário, de permitir e estimular a interferência nos encontros para que ele se aproprie das práticas e de suas resultantes.

Na UMT, as participantes não abordaram experiências relacionadas à observação e/ ou imitação de sequências de movimento, mas frisaram as relações estabelecidas entre 0 professor e o usuário durante a condução das práticas corporais e relataram que os encontros 
propiciaram alterações no processo de supervisão de outros profissionais de saúde. Atribuíram tal ocorrência ao fato de elas estarem ali atuando como estudantes, observarem como se portam como professores, como executam cada movimento e como ensinam. Uma participante (Priscila) salientou nas entrevistas em grupo que a possibilidade de tocar o seu próprio corpo e o do usuário fez com que ela repensasse o modo como ministra as práticas corporais e a sua própria experiência corporal, pois tinha aprendido que tal ação não deveria ser realizada. Colocações como essa possibilitaram discussões sobre o quanto as práticas corporais são ensinadas do modo que foram aprendidas e o quanto elas poderiam se desenvolver se conhecessem outros recursos didáticos.

Ao ministrar ou participar de atividades com as práticas corporais, todos podem ampliar seus conhecimentos. Para tanto, a existência de diferentes modos de ensinar e aprender, de níveis de dificuldades e necessidades de atenção diversificadas precisa ser considerada. Há sujeitos que conseguem organizar seu corpo e seu movimento no espaço conduzindo-o e comandando-o com facilidade, mas há outros que não conseguem perceber seu corpo ao se movimentarem. Nos dois casos, o professor precisa implementar estratégias para que 0 estudante perceba o que, como, para onde e em que tempo o seu movimento pode ser realizado.

Por exemplo, ao ministrar o Lian Gong e observar como as pessoas utilizam o peso do corpo, o professor pode identificar sujeitos que impõem muita força e resistência ao se movimentarem e outros que sequer atingem a forma solicitada, pois não conseguem controlar o tônus de seus corpos. Pode olhar para isso e não se preocupar, achando que com a repetição o estudante aprenderá. Pode observar a situação e tentar demonstrar o que deve ser feito, requisitando que imite o movimento corretamente, sem explicitar onde está o problema. Os que conhecem a teoria labaniana poderão desenvolver ações específicas relativas ao uso e às peculiaridades do fator peso partindo de situações cotidianas e correlacionando a resistência do gesto (forte/ fraco) com as sensações corporais (leve/pesado), para depois avaliar o progresso na qualidade de execução.

Através dos depoimentos constatou-se que as participantes transferiram as experiências vivenciadas para o cotidiano profissional. Isso ocorreu porque a teoria apresentada possibilitou que o sujeito atribuísse significados ao seu corpo e ao seu movimento através da apreensão de formas de observar, descrever, analisar, assimilar e agir de forma responsável sobre as suas características de movimentação. A teoria labaniana não privilegia a repetição de formas, mas aponta o que deve e pode ser observado para que o ser humano compreenda a situação existencial que faz com que determinado padrão de movimento exista.

Ao preconizar que "[...] precisamos empregar todo o nosso ser no material do movimento e descobrir a facilidade ou dificuldade que temos para utilizá-lo e manejá-lo ao dançar" (LABAN, 1990, p.114), Laban sugere que o professor aja como um guia e que cada estudante seja estimulado a ser agente de sua própria aprendizagem. Para isso, ele precisa ser capaz de envolver cada um de uma forma diferente, incentivando descobertas, desenvolvimento do caráter, da curiosidade e da possibilidade de olhar para o erro com generosidade.

Tais premissas auxiliam os profissionais que atuam no campo da saúde a levar em consideração que trabalhar com o corpo exige muito mais do que reproduzir formas, treinar, disciplinar o físico e/ou queimar calorias, a constatar a possibilidade de usar o movimento com autonomia e de elaborar criativamente estratégias de ensino-aprendizado que possam ser implementadas nas ações com as práticas corporais. 


\subsection{A QUALIDADE DAS INTERAÇÕES VERBAIS PROCESSADAS NA RELAÇÃO PROFISSIONAL/USUÁRIO}

No tocante aos processos de ensino-aprendizagem estabelecidos pela qualidade das interações verbais, verificou-se que a teoria labaniana auxiliou as participantes a ampliar o vocabulário, a descrever com mais precisão as nuances do movimento e a comunicar-se melhor. Foi reconhecida a importância do uso intencional da palavra e foi constatado que nem sempre o usuário entende aquilo que o profissional está requisitando que seja feito.

Para ilustrar, há a narração de Rosa, que demonstra como o uso de um vocabulário diferenciado a ajudou a sanar uma dificuldade do usuário:

Eu tenho o exemplo [...] relativo ao movimento que as pessoas põem a mão para trás [...]. Eu não conseguia convencer que não é esticando, pondo força. E aí, vivenciando essa questão do tempo, do deslizar eu dei conta de passar isto para as pessoas [...] eu consegui falar desses princípios, do peso, do tempo do movimento [...] foi incrível porque consegui perceber que você trazia vários vocabulários para coisas distintas [...]. Meu grupo consegue hoje executar e eu não vejo as pessoas com as dificuldades que tinham e que eu não dava conta de me comunicar e passar o que eu queria. (Rosa - UMT -EG).

E de Mary, que pontua a necessidade de diversificar o uso da palavra:

O que mais me chama a atenção é a possibilidade de descrever o movimento. [...] Algumas palavras, alguns conceitos me ajudaram a descrever o movimento de uma maneira diferente do que normalmente eu descrevia. Eu acho que isso ajuda o outro também. [...] tenho procurado diversificar na aula porque a gente sempre acaba falando do mesmo jeito. [...] Há a questão de observar o movimento e a questão do falar. (Mary - UMT - EG).

Tais comentários corroboram Laban (1990, p.34) ao declarar que "a composição do movimento pode ser comparada à linguagem oral. Assim como as palavras são formadas por letras, os movimentos são formados por elementos". Pensar em termos desses elementos estimula a atividade mental e favorece, devido às múltiplas combinações de esforços existentes, o discernimento do conteúdo que está por trás da ação.

Honda (1995), ao estudar como ensinar Tai Chi, chegou ao mesmo resultado e explicitou que a linguagem proposta por Laban propicia a distinção de tonalidades, de coloridos que fazem com que o professor seja capaz de esmiuçar as diferentes ações encontradas no cotidiano, independentemente de interpretações culturais, históricas e individuais sobre 0 movimento. Groff (1995, p.27), ao escrever sobre esse assunto, afirmou que o movimento contém um complexo enlace de elementos e que a teoria labaniana abarca "diferentes conceitos e vocábulos, os quais permitem ao observador identificar as mais salientes minúcias do movimento e relatá-la" permitindo a compreensão tanto do "como" quanto "do quê" executa.

Discussões sobre a importância da comunicação verbal não ocorreram no CECCO. Contudo, esses profissionais relataram as dificuldades encontradas no processo de implantação das práticas corporais na unidade e enfatizaram a necessidade de ampliação do espaço disponibilizado para a realização de capacitações.

Através desse tipo de ocorrência nos certificamos das demandas e reações peculiares de cada grupo, fato que ratifica a necessidade de se repensar a formação dos profissionais de saúde considerando as relações que são estabelecidas entre tais sujeitos e o cotidiano do serviço de saúde. 


\subsection{A DIVERSIFICAÇÃO DE ESTRATÉGIAS DIDÁTICAS, A CRIATIVIDADE E A LUDICIDADE}

A teoria labaniana propicia a identificação dos múltiplos esforços inerentes ao movimento e à compreensão que educar e ensinar são atos que acontecem na medida em que o professor escolhe um caminho e seu aluno aceita segui-lo, entendê-lo e recriá-lo. Isso pode ser percebido nos relatos em que as participantes demonstraram gostar da possibilidade de criar novas formas de agir, de se expressar, de se conhecer e valorizar o potencial e singularidade de cada um.

No CECCO, uma participante (Bruna) narrou que os encontros fizeram com que ela se sentisse mais livre para desenvolver as suas aulas e com que estabelecesse propostas diferenciadas. Ela afirmou que a forma como aprendeu uma determinada prática interferiu no modo como ela a ensina e que o conjunto de movimentos a serem executados, que deveria favorecer o seu trabalho, engessou o seu cotidiano e as relações que estabelece com os usuários. Outra (Amanda) mencionou que foi capaz de alterar o direcionamento de suas aulas e destacou que o fato de cada encontro ter sido diferente estimulou o seu interesse e a sua criatividade. Uma terceira (Mariana) disse que os encontros mostraram que é possível conduzir as práticas sem focalizar na repetição de determinada sequência de movimentos e que a variação de estratégias didáticas, a criatividade do professor, é importante para os usuários.

Esses relatos mostraram que a formação desses profissionais apresenta algumas lacunas, pois o modo como aprenderam a trabalhar com as práticas corporais esteve, prioritariamente, focalizado na repetição de formas. Elas não tinham tido a oportunidade de ver os encontros realizados por meio das práticas corporais como uma estratégia de ensino, um meio de aguçar a criatividade, de mobilizar conhecimentos sobre si mesmo e sobre o outro.

Schwartz (1993) buscou identificar alguns motivos para se cultivar a criatividade através da dança. Para tanto, entrevistou professores, utilizou as teorias de Howard Gardner e as proposições de Laban. Esses dois autores concebem a criatividade como um processo que afeta a maneira como o ser humano vive e se relaciona com o mundo e com os outros. A autora verificou uma leitura equivocada acerca dos conhecimentos desenvolvidos por meio da dança. Muitos professores consideraram que essa arte desenvolve, apenas, a inteligência cinestésica. Ela demonstrou que a dança desenvolve, também, a inteligência espacial, musical, matemática, linguística, interpessoal e as capacidades expressivas do sujeito. E que a criatividade nasce da evocação de um mundo simbólico, de um arcabouço de ideias e permite que o homem ame sua criação antes de ela existir, se aproprie de sua produção, de sua subjetividade, de um jeito inalcançável por outras vias. Verificou, ainda, que vivências criativas contextualizadas e fundamentadas nos temas de movimento propostos por Laban auxiliam os alunos a assumir riscos, nadar em águas desconhecidas e, com isto, maximizar o seu potencial existencial.

Para que o profissional que atua com as práticas corporais possa organizar a atenção e o cuidado, atender às necessidades de saúde de cada usuário e de cada grupo, avaliar periodicamente o seu próprio desempenho e o contexto em que atua, ele precisa de uma formação continuada e ampliada que o faça refletir sobre os processos pedagógicos estabelecidos em suas aulas, sobre os esforços de movimento presentes nas modalidades implementadas e sobre os impactos de suas escolhas em determinado grupo. Essa formação deve auxiliá-lo a selecionar e ordenar habilidades a serem desenvolvidas, a eleger conteúdos 
que estimulem a criatividade, a reconhecer diferentes pontos de vista, a avaliar as ações bemsucedidas e reinventar aquelas que, por algum motivo, precisem ser aprimoradas.

Na UMT, ao invés da criatividade, as participantes citaram a ludicidade, a possibilidade de brincar, de se divertir e ao mesmo tempo cuidar, conforme exemplificado por Lia:

Para você tratar uma doença [...] não precisa ser sofrido. [...] pode ser de uma forma mais descontraída, mais alegre, mais prazerosa. [...] essas intervenções vieram ao encontro desta questão, visto que normalmente nós ministramos as práticas de uma forma mais séria, mais contida. E de repente a gente viu que dá para soltar, que dá para brincar, que dá para ser lúdico, divertido e que dessa forma não vai deixar de cuidar do outro e de trazer, de cumprir esta proposta primeira que a gente tem que é de fazer saúde a partir das práticas corporais. (Lia - UMT - EG).

Pormeio deste e de outros depoimentos constatou-se que a liberdade e a espontaneidade proporcionadas pelas vivências permitiram que as participantes se destituíssem do mimetismo, que explorassem a criatividade e sistematizassem outros modos de atuar com as práticas corporais. Isso não significa que o vocabulário das diferentes modalidades de práticas tenha sido abandonado, mas que, no decorrer do processo, ele foi ressignificado.

$\mathrm{Na}$ busca por atribuir significados para a experiência, quatro participantes da UMT (Mônica, Mary, Priscila e Rosa) pontuaram a dificuldade de nomear os conceitos seguindo a terminologia proposta por Laban. Contudo, explicitaram que, mesmo assim, perceberam a seriedade e a complexidade das proposições e avistaram uma mudança naquilo que estão fazendo em seu cotidiano.

Tais depoimentos mostram que todos podemos testemunhar acontecimentos passados e prever, dar "uma olhadela no futuro, nas possíveis consequências de seus atos". Isso ocorre porque "uma posição corporal sempre é resultado de movimentos prévios ou a antecipação de futuros movimentos, que tanto deixam sua marca impressa na postura do corpo, como anunciam a próxima", mas também porque podemos detectar certas incongruências em nossos impulsos internos, desveladas pelas formas e ritmos de nossos movimentos (LABAN, 1978, p. 175). Nas ações funcionais, realizadas no cotidiano, tais constatações podem ser consideradas irrelevantes. Todavia, nas ações com as práticas corporais, o entendimento desses processos auxilia o profissional de saúde a estabelecer procedimentos e produzir cuidados com mais efetivos através do movimento e a percepção da singularidade de cada usuário.

A relação existente entre a demanda e o acesso aos serviços de saúde também foi tema de debate. As participantes declararam que as práticas corporais permitem que muitas pessoas sejam atendidas, propiciam a criação de vínculos, relações humanizadas e resultados que nenhum outro serviço de saúde disponível no SUS é capaz de alcançar. Por isso, consideram importante aprimorar o modo de ministrá-las.

Em síntese, verificou-se que os encontros auxiliaram as participantes a reverem suas posturas como condutores de práticas corporais, fizeram com que se integrassem de outra forma, com que criassem, brincassem e refinassem os seus modos de aprender e de ensinar.

\subsection{A CONVIVÊNCIA ENTRE OS INTEGRANTES DA EQUIPE, CRÍTICAS E ELOGIOS}

Embora o trabalho em equipe possa ser considerado um importante pressuposto para 
fosse "uma panaceia capaz de solucionar [...] os problemas das práticas de saúde decorrentes da complexidade do processo saúde-doença [...]" (PAIM, 2002, p.444). Isso ocorre porque a integração entre membros de uma equipe demanda tempo e mudanças nos padrões de atuação individual e coletivo, envolve o agenciamento coletivo de responsabilidades, a pactuação de consensos em relação aos objetivos e resultados a serem alcançados, o manejo de conflitos nos momentos de planejamento, execução e avaliação do trabalho e a produção de um projeto pertinente às necessidades de saúde dos usuários (CAMPOS et al., 2008).

Todos as participantes relataram que no cotidiano do serviço faltam espaços para reflexões coletivas sobre as ações executadas com práticas corporais, pois as reuniões semanais, normalmente, concentram-se na solução dos problemas administrativos. Destacaram que, com os encontros, perceberam mudanças no modo de agir e interagir no trabalho, pois elas puderam conviver de outra maneira reconhecendo o que seu colega executa, como e quais estratégias utiliza. Esse resultado foi gerado porque o trabalho com o corpo em movimento tem um diferencial. Possibilita que o sujeito olhe para si mesmo e para seus colegas e não para a hierarquia das relações, permite uma expressão liberta e oportuniza um modo diferenciado de lidar com as inseguranças, incertezas, sentimentos, desejos e afetos.

Quanto às críticas, todas fizeram considerações sobre a quantidade de encontros realizados e pontuaram que deveria haver mais tempo para o aprofundamento do conteúdo, especialmente na aplicação da teoria labaniana nas diferentes modalidades de práticas corporais. Quanto aos elogios, os depoimentos mostraram o quanto os conhecimentos apreendidos, as estratégias didáticas utilizadas e seus desdobramentos "para fora da sala de aula" foram importantes para as participantes e o quanto gostariam que outros profissionais tivessem participado da pesquisa.

\section{CONSIDERAÇÕES FINAIS}

Ao estudar como a teoria labaniana pode contribuir com o trabalho dos profissionais de saúde que atuam ou desejam atuar com as práticas corporais no SUS, três formas de conduzir as ações com as práticas corporais foram identificadas. Discussões sobre tais proposições possibilitaram: o exame de modos de se estabelecer relações de cuidado através da percepção do corpo em movimento; reflexões sobre como reconhecer o uso de padrões de movimento e lidar com as dificuldades dos usuários; o entendimento de formas de se contextualizar proposições, tendo como suporte os conhecimentos prévios dos usuários; o reconhecimento da importância das palavras, do desenvolvimento da expressividade e da criatividade na orientação das ações com as práticas corporais; a oportunidade de ver o erro como descoberta; e a identificação de princípios, apoiados em fatores de movimento, que podem ser utilizados em qualquer modalidade de prática corporal.

Ademais, os encontros revelaram modos de ser e de se comunicar no/com o mundo pelo corpo e de lidar com as circunstâncias sociais, econômicas, ambientais e afetivas que interferem na atuação dos profissionais que trabalham com as práticas corporais, dentre os quais é possível citar: a dificuldade para o acesso a capacitações e uso do serviço que prestam, a escassez de recursos materiais e horários para conversar sobre o que desenvolvem nos diferentes equipamentos de saúde em que atuam. Isso ocorreu porque as proposições consideraram as experiências dos sujeitos e seus vínculos, favoreceram o estabelecimento de 
relações pessoais diferenciadas e o entendimento de corresponsabilidades na coordenação do cuidado, permitindo que cada profissional utilizasse o que foi apreendido de sua maneira, com alegria, criatividade e criticidade; são aprendizados que não estão especificados nas políticas públicas que versam sobre a implantação destas atividades no SUS, mas que são importantes para 0 atendimento das diretrizes e princípios deste serviço.

Os depoimentos demonstraram, inicialmente, compreensões individuais, subjetivas e singulares acerca do trabalho com as práticas corporais no serviço público de saúde. Contudo, no decorrer dos encontros questões e dificuldades de ordem coletiva foram identificadas e problematizadas.

Ao avaliar os resultados verificou-se a complexidade do trabalho desenvolvido pelos profissionais que atuam com práticas corporais e constatou-se que a organização da atenção e do cuidado em saúde precisa considerar o aprimoramento da observação, do reconhecimento e da descrição dos diferentes esforços humanos; da variedade de matizes interiores (impulsos, ímpetos, desejos) e exteriores possíveis de serem vivenciados, especialmente, diante do modelo de atendimento médico e de formação em saúde prevalentes, que ainda se voltam para a cura de doenças e não para a ampliação do potencial de vida, das habilidades e de conhecimentos das pessoas.

Este trabalho se voltou para essa direção, para a construção de trajetórias didáticas, expressivas, lúdicas e criativas que estimulassem as participantes a repensar o seu cotidiano, suas formas de lidar com as práticas corporais e com os demais serviços de saúde que operam sobre os efeitos do adoecer e incidem sobre os modos de viver.

À medida que os encontros propiciaram situações desafiadoras, que exigiram a percepção dos esforços imersos no corpo e no movimento, outros modos de compor o trabalho com as práticas corporais foram revelados. Com isso, a força e o potencial da teoria labaniana, no que se refere ao esclarecimento de conteúdos e estratégias a serem desenvolvidas nas ações com qualquer modalidade de prática corporal foi revelada. Além disso, foi possível vislumbrar como seria se os profissionais que atuam na rede de atenção básica tivessem a oportunidade de conhecer aspectos desta teoria e fossem capacitados para utilizá-los em suas ações com as práticas corporais. Tais conhecimentos poderiam impactar, como foi demonstrado, no planejamento dos encontros, no acolhimento dos usuários e na qualidade da orientação fornecida nas aulas. Talvez, com esses conhecimentos, mas não só, as ações com as práticas corporais fossem valorizadas para além de seu impacto na saúde física. Quem sabe, tais referenciais pudessem auxiliar na desconstrução da mecanicidade prevalente que acomete o trabalho com práticas codificadas e pudessem fortalecer e estimular cada professor a recriar permanentemente seus modos de ensinar, produzindo um cuidado singular, que possa estar vinculado a:

[...] práticas cuidadoras de indivíduos e coletividades; práticas de afirmação da vida, sob todas as suas formas inventivas e criativas de mais saúde; práticas de responsabilidade com as pessoas e coletividades pela sua melhor saúde individual e coletiva; práticas de desenvolvimento e realização de um sistema de saúde com capacidade de proteção de vida e saúde e práticas de participação e solidariedade que tenham projetos de democracia, cidadania em direitos sociais (CARVALHO; CECCIM, 2006, p.155).

Enfim, constatou-se que a teoria labaniana atuou, justamente, na constituição e no aprimoramento do trabalho com as práticas corporais. Consequentemente, conclui-se que ela 
é um importante referencial para a formação de profissionais que atuam com tais ações, o que aponta para a necessidade de se investir na difusão desse referencial nos serviços públicos de saúde.

\section{REFERÊNCIAS}

BRASIL. Ministério da Saúde. Política Nacional de Promoção da Saúde. Brasília, 2006a.

BRASIL. Ministério da Saúde. Política Nacional de Práticas Integrativas e Complementares no SUS. Brasília, 2006b.

CAMPOS, Gastão W. et al. (org.). Tratado de saúde coletiva. São Paulo: Hucitec, 2006.

CARVALHO, Yara M. Práticas corporais e comunidade: um projeto de educação física no Centro de Saúde Escola Samuel B. Pessoa. In: FRAGA, Alex Branco; WACHS, Felipe. Educação física e saúde coletiva. 2. ed. Porto Alegre: Editora da UFRGS, 2007. p. 63-72.

CARVALHO, Yara M; CECCIM, Ricardo B. Formação e Educação em Saúde: aprendizados com a saúde coletiva. In: CAMPOS, Gastão Wagner (org.) et al. Tratado de saúde coletiva. São Paulo: Hucitec, 2006. p. 149-182.

GALLAHUE, David L; OZMUN, John C, GOODWAY, Jacqueline D. Compreendendo o desenvolvimento motor: bebês, crianças, adolescentes e adultos. 7. ed. Porto Alegre: Artmed, 2013.

GROFF, Ed. Laban Movement Analysis: charting the ineffable domain of human movement. Journal of Physical Education, Recreation \& Dance, v. 2, n.66, p. 27-30, 1995.

HODGSON, John. Mastering Movement. The Life and Work of Rudolf Laban. London: Methuen, 2001.

HONDA, Charlotte M. Cultural Diversity: Tai Chi Chuan and Laban Movement Analysis. Journal of Physical Education, Recreation \& Dance, v. 66, n. 2, p. 38-40, 1995.

LABAN, Rudolf. Domínio do Movimento. São Paulo: Summus, 1978.

LABAN, Rudolf. Dança Educativa Moderna. São Paulo: Ícone, 1990.

PAIM, Jairnilson S. A investigação em sistemas e serviços de Saúde. In: PAIM, Jairnilson S. Saúde política e reforma sanitária. Salvador: CEPS/ISC, 2002. p. 435-44.

SCHWARTZ, Peggy. Creativity and dance: implications for pedagogy and policy. Arts Education Policy Review, v.1, n. 95, p. 8-16, 1993.

ZAGATTI, Franca. L'erranza pedagogica di Rudolf Laban nei sentieri del corpo. Danza e Ricerca Laboratorio di studi, scritture, visioni, v.1, n. 1, p. 1-10, 2011. 